\title{
Low temperature and low irradiation induced irreversible damage of strawberry seedlings
}

\author{
C. XU* M.T. WANG ${ }^{* * * * *,+}$, Z.Q. YANG ${ }^{*, \#,+}$, and Q.T. ZHENG ${ }^{*}$ \\ Collaborative Innovation Center on Forecast and Evaluation of Meteorological Disasters, Nanjing University \\ of Information Science and Technology, Nanjing, Jiangsu Province, China* \\ Sichuan Meteorological Observatory, Chengdu, Sichuan Province, China** \\ Water-Saving Agriculture in Southern Hill Area Key Laboratory of Sichuan Province, Chengdu, Sichuan Province, \\ China $^{* * *}$ \\ Binjiang College, Nanjing University of Information Science and Technology, Nanjing, Jiangsu Province, China ${ }^{\#}$
}

\begin{abstract}
Low temperature (LT) and low irradiation (LI) are common factors posing a great risk to plants. The study aimed to elucidate the effects of LT and LI and recovery on the photosynthetic apparatus, photoinhibition of PSII, and reactive oxygen metabolism of strawberry seedlings. The results showed that strawberry growth slowed down or even stopped and total chlorophyll content, stomatal conductance, net photosynthetic rate, and maximal quantum yield of PSII photochemistry decreased, while intercellular $\mathrm{CO}_{2}$ concentration increased under LI, LT, and combined stress (LL). Additionally, JIP-test showed that compared to LI or LT stress, LL-stressed plants had lower quantum yields and efficiencies and functional antenna size, and higher reaction center activity. Besides, the contents of hydrogen peroxide and malondialdehyde increased, while the activity of superoxide dismutase, peroxidase, and catalase were significantly inhibited compared with the control. After the stress was relieved, the photosynthesis of LL-stressed plants recovered poorly.
\end{abstract}

Additional key words: antioxidant enzymes; chlorophyll fluorescence; malondialdehyde; photosynthesis; reactive oxygen species.

\section{Introduction}

Strawberry (Fragaria $\times$ ananassa Duch) is one of the most nutritious fruits with a large planting area in China (Zhang et al. 2009). The suitable growth temperature of strawberry seedlings is between 15 and $32^{\circ} \mathrm{C}$, and temperatures below $10^{\circ} \mathrm{C}$ can severely limit their growth and development. In addition, it is widely cultivated in single-slope solar greenhouses during winter and spring seasons. Therefore, strawberry cultivation is often subjected to low temperature and low irradiation stresses, which hinders its normal growth and fruit quality.
Temperature and light have been proven to be two important environmental factors that affect plant growth and development (Allen and Ort 2001), photosynthetic physiological traits (Singh and Singh 2015a), and fruit quality (Li et al. 2010). Photosynthesis is not only the most basic life activity of plants, but also the fundamental source of organic matter and energy, and photosynthetic organs are cold-sensitive parts of plants (Kadir et al. 2006, Jurczyk et al. 2019). The authors demonstrated that low temperature (LT) can destroy all major components of photosynthesis, including thylakoid electron transport, carbon reduction cycles, and control of stomatal conductance (Allen and

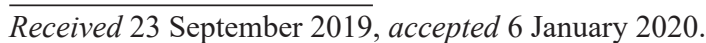

+Corresponding author; e-mail: wangmt0514@163.com (M.T. Wang), yzq@, nuist.edu.cn (Z.Q. Yang)

Abbreviations: ABS/RC - apparent antenna size of active PSII RC; CAT - catalase; $C_{\mathrm{i}}-$ intercellular $\mathrm{CO}_{2}$ concentration; $\mathrm{Chl}$ - chlorophyll; $E$ - transpiration rate; $\mathrm{DI}_{0} / \mathrm{RC}$ - effective dissipation of energy in active $\mathrm{RC} ; \mathrm{ET}_{0} / \mathrm{RC}_{-}$electron transport per active reaction center; $\mathrm{F}_{0}$ - minimal fluorescence yield of the dark-adapted state; $\mathrm{F}_{\mathrm{m}}$ - maximal fluorescence yield of the dark-adapted state; FM - fresh mass; $\mathrm{F}_{\mathrm{v}} / \mathrm{F}_{\mathrm{m}}$ - maximal quantum yield of PSII photochemistry; $g_{\mathrm{s}}$ - stomatal conductance; LI - low irradiance; LL the combination of low temperature and low irradiance; $\mathrm{L}_{\mathrm{s}}$ - stomatal limitation value; $\mathrm{LT}$ - low temperature; MDA - malondialdehyde; $\mathrm{PI}$ - leaf plastochron index; $\mathrm{PI}_{\mathrm{abs}}$ - performance index on absorption basis; $\mathrm{PI}_{\text {total }}$ - total performance index; $P_{\mathrm{N}}-$ net photosynthetic rate; $\mathrm{POD}$ - peroxidase; $\mathrm{RE}_{0} / \mathrm{RC}$ - electron flux reducing end electron acceptors at the PSI acceptor side per reaction center; $\mathrm{SOD}$ - superoxide dismutase; $\mathrm{TR}_{0} / \mathrm{RC}$ - trapped energy flux per reaction center; VPD - vapor pressure deficit; $\delta_{\mathrm{Ro}}-$ efficiency/ probability with which an electron from the intersystem electron carriers moves to reduce end electron acceptors at the PSI acceptor side; $\varphi_{\mathrm{E}_{\mathrm{o}}}-$ quantum yield for electron transport; $\varphi_{\mathrm{P}_{\mathrm{o}}}-$ maximum quantum yield for primary photochemistry; $\varphi_{\mathrm{Ro}}-$ quantum yield for reduction of end electron acceptors at the PSI acceptor side.

Acknowledgements: This work was supported by the National Key Research and Development Project of China (2019YFD1002202), the Foundation of Scientific and Technological Development of Meteorological Administration/Heavy Rain and Drought-Flood Disasters in Plateau and Basin Key Laboratory of Sichuan Province (Key Laboratory of Sichuan Province-2018-Key-05), and the Open Project Program of Key Laboratory of Agricultural Environment in Southwest mountain areas, Ministry of Agriculture and rural affairs, P. R. China (AESMA-OPP-2019006). 
Ort 2001, Singh and Singh 2015b). For example, stomatal closure following chilling may be a direct low-temperature effect on the function of guard cells, or an indirect response to an increase of intercellular $\mathrm{CO}_{2}$ concentration $\left(C_{\mathrm{i}}\right)$ caused by a chill-induced loss of Rubisco activity. Yang et al. (2016) studies show that low irradiation (LI) may block the transport of electrons in the photosystems, reduce the activity of carbon assimilation enzymes, and alter the activity of antioxidant enzymes. Therefore, low temperature and low light intensity can affect the performance and activity of photosynthetic apparatus. Chlorophyll (Chl) fluorescence is closely related to various reactions in photosynthesis and its measurement brings a lot of information on photosynthesis and effects of stress factors (such as low temperature, low irradiation or combined stress) on plant functioning (Maxwell and Johnson 2000, Baker 2008).

Under adverse stress conditions, oxidative stress is induced by the production and accumulation of reactive oxygen species (ROS), which have greater toxicity potentials on biomolecules, such as lipids, proteins, and nucleic acids (Gill and Tuteja 2010). In order to control the effects of ROS production inside and outside the chloroplast, plant cells activate photoprotective mechanisms. For instance, several antioxidant enzymes, such as catalase (CAT), peroxidase (POD), and superoxide dismutase (SOD) are produced in stressed plants to prevent the excess generation of ROS and scavenge the inevitable ROS pool (Xu et al. 2010, Suzuki et al. 2012). If the amounts of antioxidant are insufficient, and the oxidation reaction therefore cannot be reduced, ROS are produced at a high concentration and maintained in time. Then, ROS can destroy the antioxidant defense system, leading to irreversible destruction of the photosynthetic apparatus including the nuclear gene expression machinery (Munné-Bosch and Pintó-Marijuan 2016). Consequently, identifying the production of sustained ROS and the adequate activation of antioxidant responses help elucidate the extent of oxidative stress in leaves under abiotic stresses. In addition, malondialdehyde (MDA) is one of the most important and widely measured nonenzymatic forms of lipid peroxidation and is also a common indicator used to measure plant oxidative stress (Tsikas 2017).

To our knowledge, previous studies, in general, have been conducted under conditions of one factor changing (LT or LI), while ignoring the superposition effect of the combined effect, which is very common in nature. In this paper, the 'Benihoppe' strawberry was used as the experimental material to establish a two-factor control experiment of LT and LI. The aim was to determinate the effects of chilling temperature combined with low irradiation on the photosynthetic performance of strawberry seedlings, under the hypothesis that the combined stresses of LT and LI can exacerbate photoinhibition, and this inhibition is then irreversible.

\section{Materials and methods}

Experimental materials and treatments: Cultivation experiments were conducted in Venlo greenhouse of the gricultural experimental station located in Nanjing
University of Information Science and Technology from October 2018 to January 2019. The experimental strawberry cultivar was 'Benihoppe' (Fragaria $\times$ ananassa Duch., cv. 'Benihoppe') provided by the Shandong fruit tree planting base. Strawberry seedlings were planted in pots $(8 \mathrm{~cm}$ inside diameter, $10 \mathrm{~cm}$ in height) filled with nutrient soil (peat:Meteori:Perlite at $3: 1: 1$ ) and cultivated in an artificial climate chamber (TPG-2009, Australia). The illumination of the artificial climate chamber was set to $800 \mu \mathrm{mol}$ (photon) $\mathrm{m}^{-2} \mathrm{~s}^{-1}$, the temperature was set to $25 / 15^{\circ} \mathrm{C}$ (average day/night temperatures), the photoperiod was $12 / 12 \mathrm{~h}$ (day/night, day from 06:00 to $18: 00 \mathrm{~h}$ ), and the relative humidity was controlled at $65-75 \%$, which were the most suitable conditions for seedlings growth. All seedlings were watered with tap water once every two days simultaneously. When five true leaves $(>5 \mathrm{~cm})$ appeared in strawberry seedlings, potted plants with strong and similar growth were selected and transplanted into other artificial climate chambers for experimental treatment.

The experiment designed three treatments and one control, with a total of 36 plants per treatment. The temperature and illumination combinations were: $18 / 8^{\circ} \mathrm{C} \times 800 \mu \mathrm{mol}$ (photon) $\mathrm{m}^{-2} \mathrm{~s}^{-1}$ (LT), $25 / 15^{\circ} \mathrm{C} \times 200$ $\mu$ mol(photon) $\mathrm{m}^{-2} \mathrm{~s}^{-1}$ (LI), $18 / 8^{\circ} \mathrm{C} \times 200 \mu \mathrm{mol}$ (photon) $\mathrm{m}^{-2} \mathrm{~s}^{-1}$ (LL), and $25 / 15^{\circ} \mathrm{C} \times 800 \mu \mathrm{mol}$ (photon) $\mathrm{m}^{-2} \mathrm{~s}^{-1}$ (Control), respectively. The experimental photoperiod was $12 / 12 \mathrm{~h}$ and the relative humidity was $65-75 \%$. Strawberry seedlings were stressed for $10 \mathrm{~d}$ in the LT, LI, and LL conditions, respectively, and then moved to the control conditions for 15-d recovery. The corresponding gas exchange, Chl fluorescence, and biochemical and physiological parameters were determined or analyzed after $1,4,7$, and $10 \mathrm{~d}$ of the treatments and after 5, 10, and $15 \mathrm{~d}$ for the recovery. All measurements were carried out on the fully expanded healthy functional leaves with at least three replicates from each treatment.

Leaf plastochron index (PI): The determination of PI was based on the work of Coleman and Greyson (1976). $\mathrm{PI}=\mathrm{n}+\left(\operatorname{lnL_{\mathrm {n}}}-\operatorname{lnR}\right) /\left(\operatorname{lnL}_{\mathrm{n}}-\ln \mathrm{L}_{(\mathrm{n}+1)}\right)$, where $\mathrm{R}$ is the reference length $(\mathrm{R}=10 \mathrm{~mm}), \mathrm{n}$ is the number of leaves longer than the reference length, $\mathrm{L}_{\mathrm{n}}$ and $\mathrm{L}_{(\mathrm{n}+1)}$ are the length of the $\mathrm{n}^{\text {th }}$ and $(\mathrm{n}+1)^{\text {th }}$ leaves, respectively.

Photosynthetic pigments: The determination of Chl $a$ and Chl $b$ was performed using the method of Netto et al. (2005) with minor improvements. Fresh and chopped leaf samples $(0.2 \mathrm{~g})$ were immersed in a $25-\mathrm{mL}$ test tube containing $95 \%$ ethanol and sealed it in the dark for $48 \mathrm{~h}$ until the Chl was completely extracted. Absorbance values (ABS) were measured at 663, 649, and $665 \mathrm{~nm}$ using an ultraviolet spectrophotometer (Cary50 Conc UV-VIS, Varian, Victoria, Australia), and then the concentrations of Chl $a$, Chl $b$, and total chlorophyll $\left(\mathrm{Chl}_{\mathrm{T}}\right)$ were calculated according to the following formula. Chl $a=$ $13.95 \mathrm{~A}_{665}-6.88 \mathrm{~A}_{649}$, Chl $b=24.95 \mathrm{~A}_{649}-7.32 \mathrm{~A}_{665}$, $\mathrm{Chl}_{\mathrm{T}}=\mathrm{Chl} a+\mathrm{Chl} b=20.29 \mathrm{~A}_{645}-8.05 \mathrm{~A}_{663}$. The content of Chl was expressed as $\mathrm{mg} \mathrm{g}^{-1}(\mathrm{FM})$.

Gas-exchange parameters were measured on the $5^{\text {th }}-7^{\text {th }}$ fully expanded functional leaves of the plants with a 
Li-6400 open system portable photosynthesis meter (LI-COR Inc.) from 9:00 to 11:00 h. Leaf chamber $\left(6 \mathrm{~cm}^{2}\right)$ conditions were set at a flow rate of $500 \mu \mathrm{mol} \mathrm{s}{ }^{-1}$ with 400 ppm $\mathrm{CO}_{2}$, and irradiance was set at $1,000 \mu \mathrm{mol}$ (photon) $\mathrm{m}^{-2} \mathrm{~s}^{-1}$. Before the measurement, a leaf sample was induced with PPFD of $1,000 \mu \mathrm{mol} \mathrm{m}^{-2} \mathrm{~s}^{-1}$ for $20 \mathrm{~min}$ (Guidi and Calatayud 2014). Measurements included net $\mathrm{CO}_{2}$ assimilation rate $\left(P_{\mathrm{N}}\right)$, intercellular $\mathrm{CO}_{2}$ concentration $\left(C_{\mathrm{i}}\right)$, stomatal conductance $\left(g_{\mathrm{s}}\right)$, vapour pressure deficit (VPD), transpiration rate $(E)$, which were recorded automatically by $L i-6400$. Stomatal limitation value $\left(\mathrm{L}_{\mathrm{s}}\right)$ was calculated based on the following formula: $\mathrm{L}_{\mathrm{s}}[\%]=\left[\left(C_{\mathrm{a}}-C_{\mathrm{i}}\right) / C_{\mathrm{a}}\right] \times$ 100 (Lu et al. 2017), where $C_{\mathrm{a}}$ and $C_{\mathrm{i}}$ is atmospheric and intercellular $\mathrm{CO}_{2}$ concentration, respectively.

Chl fluorescence parameters and JIP-test: Leaf Chl fluorescence $(\mathrm{ChlF})$ measurements were performed on the $5^{\text {th }}-7^{\text {th }}$ fully expanded functional leaves of the plants by using a Handy PEA fluorimeter (Hansatech Instruments Ltd., King's Lynn, UK) after 30-min dark adaptation before measurement. Maximal quantum yield of PSII photochemistry $\left(\mathrm{F}_{\mathrm{v}} / \mathrm{F}_{\mathrm{m}}\right)$, minimal fluorescence yield of the dark-adapted state $\left(\mathrm{F}_{0}\right)$, maximal fluorescence yield of the dark-adapted state $\left(\mathrm{F}_{\mathrm{m}}\right)$, and variable fluorescence $\left(\mathrm{F}_{\mathrm{v}}\right)$ were automatically monitored (Kalaji et al. 2018b). The fast acquisition kinetics of Chl $a$ fluorescence was also measured by the Handy PEA fluorimeter, which included four phases of $\mathrm{O}, \mathrm{J}, \mathrm{I}$, and $\mathrm{P}$, where $\mathrm{O}$ is the initial fluorescence level, J (2 ms) and I (30 ms) are intermediate levels, and P (500 ms-1 s) is the peak level (Yusuf et al. 2010). The 'OJIP' curves were analyzed by the JIP-test method. Based on the JIP-test, many parameters reflecting the photosynthetic activity of PSII were calculated (Yusuf et al. 2010, Lu et al. 2019): (1) performance indexes: $\mathrm{PI}_{\mathrm{abs}}=(\mathrm{RC} / \mathrm{ABS}) \cdot\left[\varphi_{\mathrm{Po}} /\left(1-\varphi_{\mathrm{Po}}\right)\right] \cdot\left[\varphi_{0} /\left(1-\varphi_{0}\right)\right], \mathrm{PI}_{\text {total }}=$ $\mathrm{PI}_{\text {abs }} \cdot\left[\mathrm{RE}_{0} /\left(\mathrm{ET}_{0}-\mathrm{RE}_{0}\right)\right]$; (2) quantum yields and efficiencies: $\varphi_{\mathrm{P}_{\mathrm{o}}}=\mathrm{TP}_{0} / \mathrm{ABS}=\left[1-\left(\mathrm{F}_{0} / \mathrm{F}_{\mathrm{m}}\right)\right], \varphi_{\mathrm{Eo}}=\mathrm{ET}_{0} / \mathrm{ABS}=$ $\left[1-\left(\mathrm{F}_{0} / \mathrm{F}_{\mathrm{m}}\right)\right] \psi_{\mathrm{Eo}}, \varphi_{\mathrm{Ro}}=\mathrm{RE}_{0} / \mathrm{ABS}=\left[1-\left(\mathrm{F}_{0} / \mathrm{F}_{\mathrm{m}}\right)\right] \psi_{\text {Eo }} \delta_{\mathrm{Ro}}$, $\psi_{\mathrm{Eo}}=\mathrm{ET}_{0} / \mathrm{TP}_{0}=\left(1-\mathrm{V}_{\mathrm{J}}\right)$, and $\delta_{\mathrm{Ro}}=\mathrm{RE}_{0} / \mathrm{ET}_{0}=\left(1-\mathrm{V}_{\mathrm{I}}\right) /$ $\left(1-\mathrm{V}_{\mathrm{J}}\right)$; $(3)$ energy fluxes: $\mathrm{ABS} / \mathrm{RC}=\mathrm{M}_{0}\left(1 / \mathrm{V}_{\mathrm{J}}\right) \cdot\left(1 / \varphi_{\mathrm{Po}_{\mathrm{O}}}\right)$, $\mathrm{TP}_{0} / \mathrm{RC}=\mathrm{M}_{0}\left(1 / \mathrm{V}_{\mathrm{J}}\right), \mathrm{ET}_{0} / \mathrm{RC}=\mathrm{M}_{0}\left(1 / \mathrm{V}_{\mathrm{J}}\right) \cdot \varphi_{0}$, and $\mathrm{RE}_{0} / \mathrm{RC}=$ $\mathrm{M}_{0}\left(1 / \mathrm{V}_{\mathrm{J}}\right) \psi_{\mathrm{Eo}} \delta_{\mathrm{Ro}}$.

Antioxidant enzymes activities: Fresh leaf samples $(0.5 \mathrm{~g})$ without main leaf vein were ground using a mortar and pestle together with $5 \mathrm{~mL}$ of phosphate buffer $(\mathrm{pH} 7.8)$ placed in an ice bath. The homogenate was centrifuged at $4,000 \mathrm{rpm}$ at $4^{\circ} \mathrm{C}$ for $20 \mathrm{~min}$. The supernatant was used to analyze the activity of antioxidant enzymes. All measurements were slightly modified based on actual conditions.

Catalase (CAT; EC 1.11.1.6) activity was measured by potassium permanganate titration method described by Aebi (1984). CAT activity was expressed as $\mu \mathrm{mol}\left(\mathrm{H}_{2} \mathrm{O}_{2}\right.$ oxidized) $\mathrm{min}^{-1} \mathrm{mg}^{-1}$ (protein). Peroxidase (POD; EC 1.11.1.7) activity was assayed by guaiacol chromogenic method based on the method of Kwak et al. (1995). POD activity was expressed as $\mu \mathrm{mol}\left(\mathrm{H}_{2} \mathrm{O}_{2}\right.$ reduced $) \mathrm{min}^{-1}$ $\mathrm{mg}^{-1}$ (protein). Superoxide dismutase (SOD; EC 1.15.1.1) activity was determined by nitroblue tetrazolium (NBT) method according to Dhindsa et al. (1981). SOD activity was expressed as $\mathrm{U} \mathrm{mg}^{-1}$ (protein).

Lipid peroxidation and $\mathrm{H}_{2} \mathrm{O}_{2}$ determination: Lipid peroxidation was estimated based on the content of malondialdehyde (MDA). MDA content was determined according to the method described by Hodges et al. (1999) with minor modifications. Leaf tissues (0.2 g) were homogenized in $5 \mathrm{ml}$ of $50 \mathrm{mM}$ sodium phosphate buffer ( $\mathrm{pH}$ 6.5). The supernatant $(2 \mathrm{ml})$ was mixed with 2 $\mathrm{mL}$ of $0.6 \%$ thiobarbituric acid (TBA) and incubated for $30 \mathrm{~min}$ at $100^{\circ} \mathrm{C}$ to produce the chromogen thiobarbituric acid-malondialdehyde (TBA-MDA). The absorbance was measured at 440, 532, and $600 \mathrm{~nm}$ by using the spectrophotometer (Cary 50 Conc UV-VIS, Varian, Victoria, Australia). Then, the content of MDA was calculated and expressed as nmol g-1 $\mathrm{FM}^{-1}$.

$\mathrm{H}_{2} \mathrm{O}_{2}$ content was determined using the method of Ansari et al. (2018). Leaf tissues (0.2 g) were homogenized in $5 \mathrm{ml}$ of $50 \mathrm{mM}$ sodium phosphate buffer $(\mathrm{pH} 6.5)$. Supernatant $(3 \mathrm{ml})$ was mixed with $1 \mathrm{ml}$ of $0.1 \%(\mathrm{w} / \mathrm{v})$ titanium sulfate in $20 \%(\mathrm{v} / \mathrm{v}) \mathrm{H}_{2} \mathrm{SO}_{4}$ and centrifuged for $25 \mathrm{~min}$ at 4,000 $\times \mathrm{g}$. Absorbances of the supernatant were recorded at $410 \mathrm{~nm}$ with an spectrophotometer (Cary 50 Conc UV-VIS, Varian, Victoria, Australia). The concentration of $\mathrm{H}_{2} \mathrm{O}_{2}$ was expressed as $\mu \mathrm{mol} \mathrm{g} \mathrm{g}^{-1}(\mathrm{FM})$.

Data analysis: Data were presented as the mean of three replicates \pm standard deviation (SD). Statistical analysis of physiological parameters was carried out by using DPS 7.5 (Data Processing System). One-way analysis of variance (ANOVA) followed by Duncan's multiple range test between the treatments was applied to evaluate significant differences $(p<0.05)$. All graphs were drawn by GraphPad Prism 7.0 (GraphPad Prism Software Inc., San Diego, USA).

\section{Results}

Growth and Chl content: After treatment for $10 \mathrm{~d}$ under LL and LT, the PI value of strawberry plants was basically unchanged, and the growth was completely stagnant (Fig. 1). Meanwhile, the PI value increased under LI treatment, but the increment in PI was significantly lower than that of the control group. After the stress was relieved, the PI values of the plants under low irradiance and chilling treatment increased rapidly, and the increase values after recovery for $10 \mathrm{~d}$ were 1.9 and 2.1 , respectively, which were not significantly different from the increase value (2.2) in the control group. However, after recovery for $10 \mathrm{~d}$ after LL treatment, PI increased only by 1.1 , which was significantly less than that after LI treatment.

With the prolongation of weak light and low temperature stress, the total Chl content decreased continuously, and gradually increased after imposing normal temperature and light intensity conditions (Table 1). After $14 \mathrm{~d}$ of recovery, the Chl content in strawberry leaves under LI and LT treatments was not significantly different from 
that of the control group, while the Chl content under LL treatment was significantly different from the control.

Photosynthetic parameters: Photosynthetic performance of strawberry seedlings was significantly inhibited after exposure to adverse stress for $4 \mathrm{~d}$, and with the extension of stress duration, the inhibition was even more obvious (Fig. 2). After $10 \mathrm{~d}$ of treatment, the $P_{\mathrm{N}}$ under LL treatment decreased significantly by $77.2 \%$ compared to the control, and decreased by 48.6 and $59.1 \%$, respectively, under LI and LT treatments (Fig. $2 A$ ). Meanwhile, $g_{\mathrm{s}}$ and $\mathrm{L}_{\mathrm{s}}$ decreased significantly with the prolongation of each stress, but $C_{\mathrm{i}}$ increased significantly (Fig. $2 C-E$ ). During the subsequent recovery process, the $P_{\mathrm{N}}, g_{\mathrm{s}}$, and $\mathrm{L}_{\mathrm{s}}$ of the plants under $\mathrm{LL}$ treatment showed an upward trend, while the $C_{\mathrm{i}}$ showed a downward trend. The recovery rate of those parameters under LI treatment was significantly faster than that under LL treatment. In addition, the adverse stresses not only inhibited photosynthetic capacity, but also severely suppressed transpiration, i.e., all treatments caused a large rapid decline in $E$ and VPD (Fig. $2 B, F$ ).

Chl fluorescence parameters: Compared with the control, after $10 \mathrm{~d}$ of $\mathrm{LL}$ treatment, the values of $\mathrm{F}_{\mathrm{v}} / \mathrm{F}_{\mathrm{m}}, \mathrm{F}_{\mathrm{m}}$, and $\mathrm{F}_{\mathrm{v}}$ significantly decreased by $11.7,24.0$, and $32.9 \%$, respectively, while the value of $\mathrm{F}_{0}$ markedly increased by $16.3 \%$ (Fig. 3). Meanwhile, LI (or LT) stress affected those parameters slightly and there was no significant difference between LI (or LT) and control samples. After

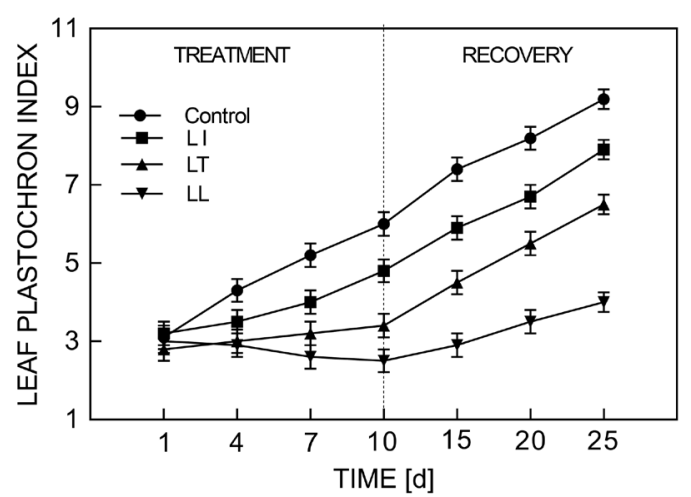

Fig. 1. Effects of chilling and low light intensity treatment and recovery on leaf plastochron index (PI). LT - low temperature; LI - low irradiance; LL - the combination of low temperature and low irradiance.
$15 \mathrm{~d}$ of recovery, none of above parameters recovered to the control level under LL treatment.

The shape of the O-J-I-P curve was influenced by LT, LI, and combined stress (Fig. 1S, supplement). The relative variable fluorescence of $\mathrm{O}-\mathrm{J}, \mathrm{J}-\mathrm{I}$, and $\mathrm{I}-\mathrm{P}$ phases in the LT, LI, and LL group were significantly lower than those in the control group after 12-d stress. After $15 \mathrm{~d}$ of recovery, the relative variable fluorescence of the LI group and the LT group was not different from that of the control group, but the J-I and I-P phases in the LL group were still significantly smaller than those in the control group. JIPtest analysis (Table 2) showed that LL stress significantly reduced the values of $\varphi_{\mathrm{Po}}, \varphi_{\mathrm{Eo}}, \delta_{\mathrm{Ro}}$, and $\varphi_{\mathrm{Ro}}$ by $11.3,15.1$, 26.8 , and $33.3 \%$, respectively, after $10 \mathrm{~d}$ of treatment, compared with the control, and those values could not recover to a similar level to that of control after $15 \mathrm{~d}$ of recovery. In contrast, the values of $\mathrm{ABS} / \mathrm{RC}, \mathrm{DI}_{0} / \mathrm{RC}$, $\mathrm{TP}_{0} / \mathrm{RC}, \mathrm{ET}_{0} / \mathrm{RC}$, and $\mathrm{RE}_{0} / \mathrm{RC}$ significantly increased by $23.0,60.0,20.8,15.2$, and $68.2 \%$, respectively, under LL stress, while they could not return to the control level after $15 \mathrm{~d}$ of recovery. In addition, strawberry plants subjected to LL stress had a lower $\mathrm{PI}_{\text {abs }}$ and $\mathrm{PI}_{\text {total }}$, which were reduced by 40 and $30 \%$, respectively, after $15 \mathrm{~d}$ of treatment compared with that in the control group, and they did not recover to the control level after $15 \mathrm{~d}$ of recovery. Similarly, the trends of all above parameters under LI and LT stress were similar to that under LL stress.

MDA and $\mathrm{H}_{2} \mathrm{O}_{2}$ : The contents of MDA and $\mathrm{H}_{2} \mathrm{O}_{2}$ increased under each treatment, and the longer stress duration, the more obvious the increase was (Fig. 4). Compared with the control, the contents of MDA and $\mathrm{H}_{2} \mathrm{O}_{2}$ increased by 49 and $72 \%$, respectively, under LL treatment for $10 \mathrm{~d}$. Similarly, LT and LL stress also enhanced both these contents after $10 \mathrm{~d}$ of treatment compared to that in control group. In addition, the contents of MDA and $\mathrm{H}_{2} \mathrm{O}_{2}$ returned to the control levels when LI-treated plants were transferred to the suitable environment for $15 \mathrm{~d}$. However, when the LT-treated and LL-treated plants were recovered for $15 \mathrm{~d}$, the contents of MDA and $\mathrm{H}_{2} \mathrm{O}_{2}$ could not decline to the control levels, showing recovery rates of 85-89 and $76-82 \%$, respectively.

Activity of antioxidant enzymes: The activities of SOD, CAT, and POD increased in all treatments (Fig. 5), particularly by $55.4,80.4$, and $65.1 \%$, respectively, under LL treatment for $10 \mathrm{~d}$ compared to that of nonstressed

Table 1. Effects of chilling and low light intensity treatment and recovery on total chlorophyll content $\left[\mathrm{mg} \mathrm{g}^{-1}(\mathrm{FM})\right]$. LT - low temperature; LI - low irradiance; LL - the combination of low temperature and low irradiance; FM - fresh mass. Different lowercase letters in same column represent significant differences at the level of 0.05 by Duncan's test. Values are means $\pm \mathrm{SD}, n=15$.

\begin{tabular}{llllll}
\hline Treatments & \multirow{2}{*}{ Control } & \multicolumn{2}{l}{ Time of treatment [d] } & \multicolumn{2}{l}{ Time of recovery [d] } \\
& & 4 & 10 & 5 & 15 \\
\hline Control & $14.27 \pm 0.15$ & $14.28 \pm 0.43^{\mathrm{a}}$ & $14.68 \pm 0.25^{\mathrm{a}}$ & $15.41 \pm 0.24^{\mathrm{a}}$ & $14.88 \pm 0.37^{\mathrm{a}}$ \\
LI & - & $13.93 \pm 0.11^{\mathrm{a}}$ & $13.48 \pm 0.20^{\mathrm{b}}$ & $14.01 \pm 0.14^{\mathrm{b}}$ & $14.75 \pm 0.18^{\mathrm{a}}$ \\
LT & - & $12.81 \pm 0.15^{\mathrm{b}}$ & $10.97 \pm 0.32^{\mathrm{c}}$ & $13.93 \pm 0.21^{\mathrm{b}}$ & $14.24 \pm 0.35^{\mathrm{a}}$ \\
LL & - & $11.82 \pm 0.15^{\mathrm{c}}$ & $10.09 \pm 0.11^{\mathrm{c}}$ & $10.53 \pm 0.15^{\mathrm{c}}$ & $11.23 \pm 0.17^{\mathrm{b}}$ \\
\hline
\end{tabular}




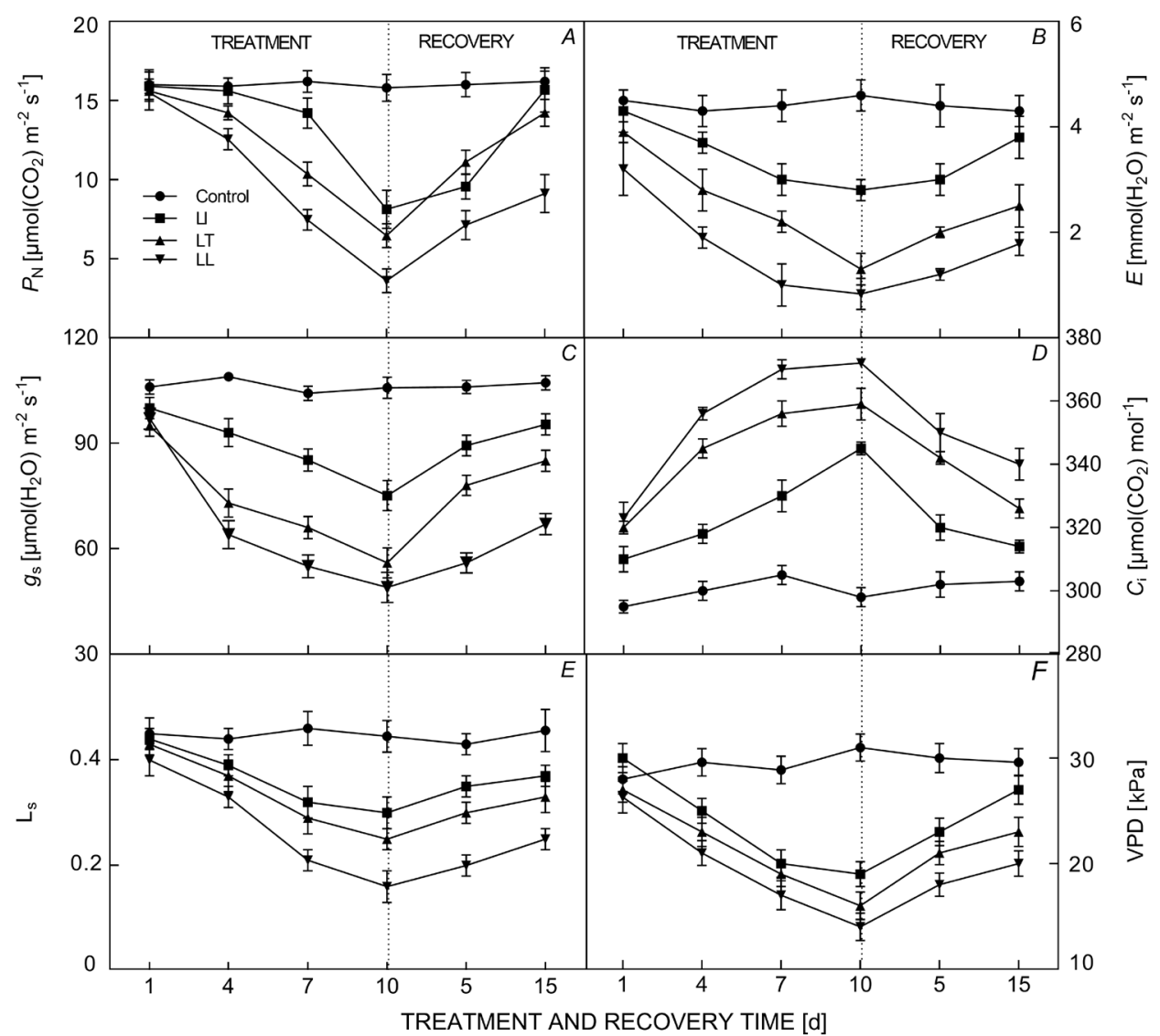

Fig. 2. Effects of chilling and low light intensity treatment and recovery on photosynthetic parameters. LT - low temperature; LI - low irradiance; LL - the combination of low temperature and low irradiance; $P_{\mathrm{N}}$ - net photosynthetic rate; $E$ - transpiration rate; $g_{\mathrm{s}}$ - stomatal conductance; $C_{\mathrm{i}}$ - intercellular $\mathrm{CO}_{2}$ concentration; $\mathrm{L}_{\mathrm{s}}-$ stomatal limitation value; VPD - vapor pressure deficit.

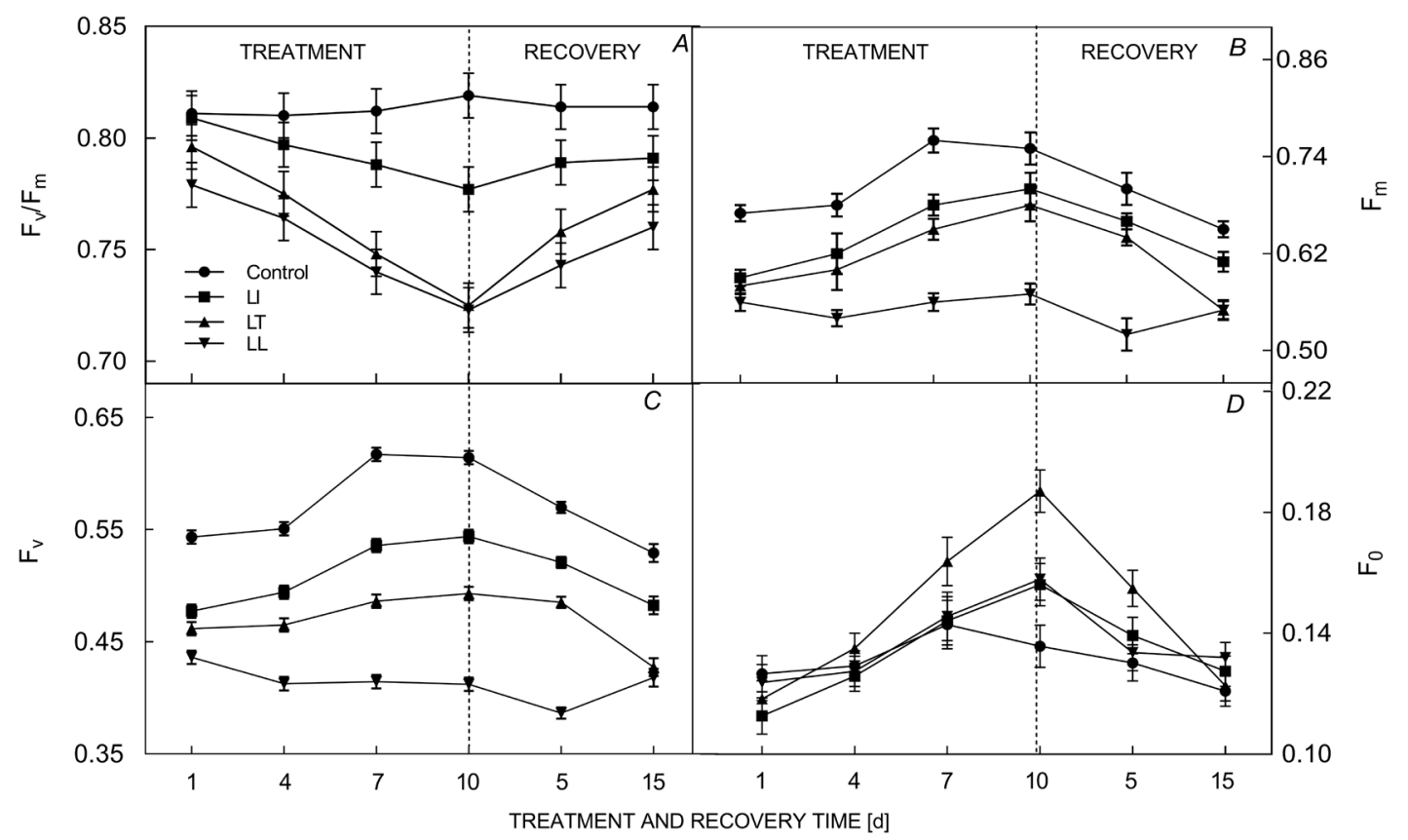

Fig. 3. Effects of chilling and low light intensity treatment and recovery on $\mathrm{F}_{\mathrm{v}} / \mathrm{F}_{\mathrm{m}}(A), \mathrm{F}_{\mathrm{m}}(B), \mathrm{F}_{\mathrm{v}}(C)$, and $\mathrm{F}_{0}(D)$. LT - low temperature; $\mathrm{LI}$ - low irradiance; LL - the combination of low temperature and low irradiance; $\mathrm{F}_{\mathrm{v}} / \mathrm{F}_{\mathrm{m}}$ - maximal quantum yield of PSII photochemistry; $\mathrm{F}_{0}$ - minimal fluorescence yield of the dark-adapted state; $\mathrm{F}_{\mathrm{m}}$ - maximal fluorescence yield of the dark-adapted state; $\mathrm{F}_{\mathrm{v}}-$ variable fluorescence. 
Table 2. Effects of chilling and low light intensity treatment and recovery on JIP-test analysis in strawberry leaves. LT - low temperature; LI - low irradiance; LL - the combination of low temperature and low irradiance; ABS/RC - apparent antenna size of active PSII per reaction center; $\mathrm{DI}_{0} / \mathrm{RC}$ - effective dissipation of energy in active per reaction center; $\mathrm{TR}_{0} / \mathrm{RC}$ - trapped energy flux per reaction center; $\mathrm{ET}_{0} / \mathrm{RC}$ - electron transport flux per reaction center; $\mathrm{RE}_{0} / \mathrm{RC}$ - electron flux reducing end electron acceptors at the PSI acceptor side per reaction center; $\varphi_{\mathrm{P}_{\mathrm{o}}}-$ maximum quantum yield for primary photochemistry; $\varphi_{\mathrm{E}}-$ quantum yield for electron transport; $\delta_{\mathrm{Ro}_{\mathrm{o}}}-$ efficiency/ probability with which an electron from the intersystem electron carriers moves to reduce end electron acceptors at the PSI acceptor side; $\varphi_{\mathrm{Ro}}$ - quantum yield for reduction of end electron acceptors at the PSI acceptor side; $\mathrm{PI}_{\mathrm{abs}}$ - performance index (potential) for energy conservation from exciton to the reduction of intersystem electron acceptors; $\mathrm{PI}_{\text {total }}$ - performance index (potential) for energy conservation from exciton to the reduction of PSI end acceptors. Different capital letters in the same line represent significant differences at the level of 0.05 by Duncan's multiple range tests, different lowercase letters in the same line represent significant differences at the level of 0.05 by Duncan's multiple range tests. Values are means $\pm \mathrm{SD}, n=15$.

\begin{tabular}{|c|c|c|c|c|c|c|c|}
\hline \multirow[t]{2}{*}{ Parameters } & \multirow[t]{2}{*}{ Control } & \multicolumn{3}{|c|}{$10 \mathrm{~d}$ of treatment } & \multicolumn{3}{|c|}{$15 \mathrm{~d}$ of recovery } \\
\hline & & LI & LT & LL & LI & $\mathrm{LT}$ & LL \\
\hline $\mathrm{ABS} / \mathrm{RC}$ & $0.87 \pm 0.05^{\mathrm{dB}}$ & $0.95 \pm 0.03^{c}$ & $1.07 \pm 0.02^{\mathrm{b}}$ & $1.17 \pm 0.09^{\mathrm{a}}$ & $0.90 \pm 0.09^{\mathrm{B}}$ & $0.99 \pm 0.04^{\mathrm{AB}}$ & $1.03 \pm 0.04^{\mathrm{A}}$ \\
\hline $\mathrm{DI}_{0} / \mathrm{RC}$ & $0.15 \pm 0.03^{\mathrm{cB}}$ & $0.19 \pm 0.02^{\mathrm{c}}$ & $0.24 \pm 0.02^{b}$ & $0.28 \pm 0.01^{\mathrm{a}}$ & $0.17 \pm 0.02^{\mathrm{B}}$ & $0.19 \pm 0.03^{\mathrm{AB}}$ & $0.23 \pm 0.02^{\mathrm{A}}$ \\
\hline $\mathrm{TP}_{0} / \mathrm{RC}$ & $0.72 \pm 0.05^{\mathrm{cB}}$ & $0.81 \pm 0.03^{\mathrm{bc}}$ & $0.87 \pm 0.04^{b}$ & $0.96 \pm 0.10^{\mathrm{a}}$ & $0.75 \pm 0.04^{\mathrm{B}}$ & $0.80 \pm 0.03^{\mathrm{AB}}$ & $0.83 \pm 0.04^{\mathrm{A}}$ \\
\hline $\mathrm{ET}_{0} / \mathrm{RC}$ & $0.46 \pm 0.02^{\mathrm{cB}}$ & $0.49 \pm 0.03^{\mathrm{bc}}$ & $0.53 \pm 0.03^{b}$ & $0.67 \pm 0.02^{\mathrm{a}}$ & $0.45 \pm 0.04^{\mathrm{B}}$ & $0.47 \pm 0.03^{\mathrm{B}}$ & $0.60 \pm 0.01^{\mathrm{A}}$ \\
\hline $\mathrm{RE}_{0} / \mathrm{RC}$ & $0.19 \pm 0.02^{\mathrm{dC}}$ & $0.24 \pm 0.02^{\mathrm{c}}$ & $0.32 \pm 0.01^{\mathrm{b}}$ & $0.44 \pm 0.02^{\mathrm{a}}$ & $0.20 \pm 0.02^{\mathrm{C}}$ & $0.27 \pm 0.03^{\mathrm{B}}$ & $0.33 \pm 0.01^{\mathrm{A}}$ \\
\hline$\varphi_{\mathrm{Po}}$ & $0.62 \pm 0.01^{\mathrm{aA}}$ & $0.61 \pm 0.02^{\mathrm{a}}$ & $0.57 \pm 0.02^{b}$ & $0.55 \pm 0.01^{\mathrm{c}}$ & $0.63 \pm 0.02^{\mathrm{A}}$ & $0.64 \pm 0.01^{\mathrm{A}}$ & $0.60 \pm 0.02^{\mathrm{B}}$ \\
\hline$\varphi_{\text {Eo }}$ & $0.53 \pm 0.04^{\mathrm{aA}}$ & $0.50 \pm 0.01^{\mathrm{a}}$ & $0.45 \pm 0.01^{\mathrm{b}}$ & $0.38 \pm 0.02^{\mathrm{c}}$ & $0.51 \pm 0.01^{\mathrm{B}}$ & $0.50 \pm 0.03^{\mathrm{B}}$ & $0.45 \pm 0.01^{\mathrm{C}}$ \\
\hline$\delta_{\mathrm{Ro}}$ & $0.41 \pm 0.03^{\mathrm{aA}}$ & $0.38 \pm 0.02^{\mathrm{a}}$ & $0.35 \pm 0.01^{\mathrm{b}}$ & $0.30 \pm 0.01^{\mathrm{c}}$ & $0.41 \pm 0.01^{\mathrm{A}}$ & $0.38 \pm 0.02^{\mathrm{A}}$ & $0.37 \pm 0.01^{\mathrm{B}}$ \\
\hline$\varphi_{\mathrm{Ro}}$ & $0.24 \pm 0.02^{\mathrm{aA}}$ & $0.22 \pm 0.01^{b}$ & $0.19 \pm 0.02^{b}$ & $0.16 \pm 0.01^{\mathrm{c}}$ & $0.24 \pm 0.02^{\mathrm{A}}$ & $0.21 \pm 0.02^{\mathrm{A}}$ & $0.19 \pm 0.03^{\mathrm{B}}$ \\
\hline $\mathrm{PI}_{\mathrm{abs}}$ & $10.71 \pm 1.35^{\mathrm{aA}}$ & $8.25 \pm 0.36^{\mathrm{b}}$ & $7.32 \pm 0.23^{\mathrm{c}}$ & $5.44 \pm 0.45^{\mathrm{d}}$ & $9.26 \pm 0.22^{\mathrm{A}}$ & $8.45 \pm 0.36^{\mathrm{B}}$ & $6.98 \pm 1.02^{\mathrm{C}}$ \\
\hline $\mathrm{PI}_{\text {total }}$ & $7.52 \pm 1.42^{\mathrm{aA}}$ & $6.58 \pm 0.18^{\mathrm{b}}$ & $5.23 \pm 0.13^{c}$ & $4.35 \pm 0.33^{\mathrm{d}}$ & $7.00 \pm 0.21^{\mathrm{A}}$ & $6.32 \pm 0.31^{\mathrm{B}}$ & $5.36 \pm 0.22^{\mathrm{C}}$ \\
\hline
\end{tabular}

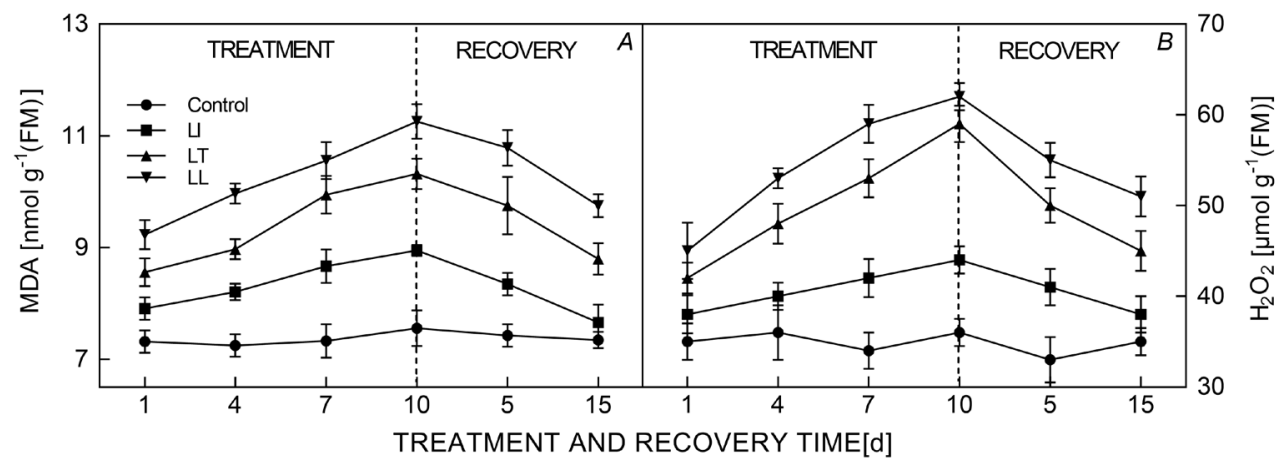

Fig. 4. Effects of chilling and low light intensity treatment and recovery on $(A)$ lipid peroxidation (expressed as MDA content) and (B) $\mathrm{H}_{2} \mathrm{O}_{2}$. LT - low temperature; LI - low irradiance; $\mathrm{LL}$ - the combination of low temperature and low irradiance; MDA - malondialdehyde; $\mathrm{H}_{2} \mathrm{O}_{2}$ - hydrogen peroxide.

strawberry seedlings. After the stress was relieved, the activities of the three enzymes decreased significantly under all treatments. On the $15^{\text {th }}$ day after recovery, the activities of the three enzymes returned to the control levels under the treatment of LI, but they were significantly different from the control under LT and LL treatments.

\section{Discussion}

Photosynthesis supplies necessary energy to form biomass and is one of the main determinators of plant growth and development (Lu et al. 2017). The change in plant growth rate is a comprehensive manifestation of its response to adverse stresses (Shu et al. 2016). In our study, chilling temperature and low light intensity caused a significant decrease in photosynthesis (Fig. 2A), which led to a slower or stagnant plant growth (Fig. 1). The reasons for the decline of photosynthesis include stomatal factors and nonstomatal factors (Farquhar and Sharkey 1982). The results in Fig. 2 showed that LI, LT, and LL stresses caused the decrease in $P_{\mathrm{N}}$ of strawberry leaves, while the $C_{\mathrm{i}}$ increased, indicating that under the above three adverse stresses, the decline of photosynthesis was not caused by a decrease in the supply of $\mathrm{CO}_{2}$ due to reduced $g_{\text {s }}$, but was caused by nonstomatal limitations (such as the loss of Rubisco and photochemical activity) that hindered the utilization of $\mathrm{CO}_{2}$, resulting in the accumulation of intercellular $\mathrm{CO}_{2}$ (Allen and Ort 2001, Gerganova et al. 2016, Liu et al. 2019). Besides, the contents of total Chl also decreased by LI, LT, and LL stresses, and after recovery for $15 \mathrm{~d}$, the total Chl content under LI and LT stresses returned to the control level, while this did not happen under LL stress (Table 1). The 


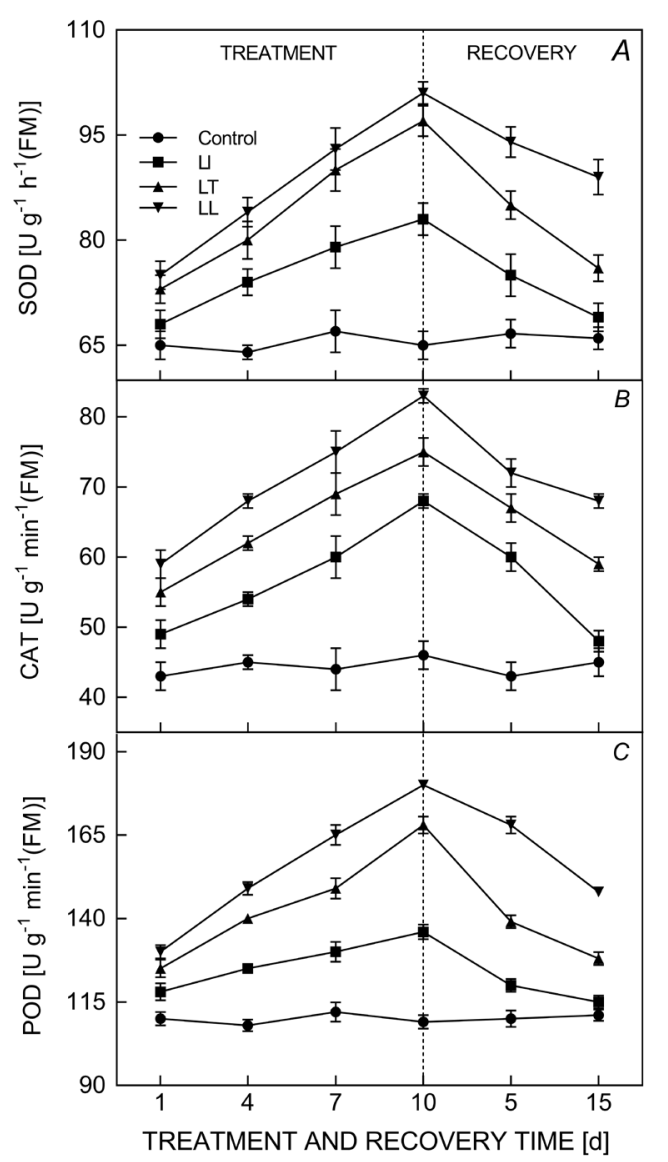

Fig. 5. Effects of chilling and low light intensity treatment and recovery on the activity of SOD $(A)$, CAT $(B)$, and POD $(C)$. LT - low temperature; LI - low irradiance; LL - the combination of low temperature and low irradiance; SOD - superoxide dismutase; CAT - catalase; POD - peroxidase.

main reason was that the combined stress aggravated the oxidative stress of cells and inactivated the membrane system, resulting in irreversible damage (Xu et al. 2019).

The sharp decrease of $P_{\mathrm{N}}$ accompanied by a significant and reversible decrease of $\mathrm{F}_{\mathrm{v}} / \mathrm{F}_{\mathrm{m}}$, which also ruled out that PSII inhibition, as the main result of LI and LT, happened especially in the process of recovery (Fig. $3 A$ ). In other words, photoinhibition under LI and LT stresses did not lead to PSII damage, but it was a photoprotective mechanism. Some previous studies on low temperature stress reported similar results (Li et al. 2003, Xu et al. 2019). However, the ratio of $F_{v} / F_{m}$ under LL stress was not recovered to the control level after $15 \mathrm{~d}$ of the recovery process, indicating that LI stress induced irreversible photoinhibition of strawberry seedlings. In addition, the decrease of photosynthesis usually caused the accumulation of excessive photon energy and photoinhibition of PSII. According to Yamamoto et al. (2014), the inactivation of the PSII reaction center was divided into two types, namely, reversible inactivation and destruction of the reaction center. In our study, compared to the control, the value of $F_{0}$ under LI stress was higher and restored to the control level after $15 \mathrm{~d}$ of recovery (Fig. 3D), implying that low light intensity induced reversible inactivation of PSII reaction center, which was consistent with the results of Yang et al. (2016). Whereas, the large decline in $\mathrm{F}_{\mathrm{m}}$ and $F_{\mathrm{v}}$ (both were unrecoverable) demonstrated that LL caused the destruction of PSII reaction center (Fig. 3B,C). Besides, LT stress induced partly irreversible inactivation ( $\mathrm{F}_{0}$ had not fully recovered) and reversible inactivation ( $\mathrm{F}_{0}$ could be recovered) of the PSII reaction center of strawberry leaves.

A sequence of parameters (Table 2) can effectively describe energy conversion, i.e., absorption flux per RC (ABS/RC), trapping flux per $\mathrm{RC}\left(\mathrm{TP}_{0} / \mathrm{RC}\right)$, electron transport flux per $\mathrm{RC}\left(\mathrm{ET}_{0} / \mathrm{RC}\right)$, and electron flux reducing end electron acceptors at the PSI acceptor side, per RC $\left(\mathrm{RE}_{0} / \mathrm{RC}\right.$ ) (Yusuf et al. 2010). Our research showed that energy absorption, transfer, and loss were more affected under combined stress than that under single stress. Strawberry plants subjected to LI and LT stresses better utilized the excitation energy and showed a higher stability of the energy fluxes system than that under LL stress. The energy fluxes per $\mathrm{RC}$ are functional parameters, while the energy fluxes per ABS are structural parameters. In our study, all the quantum yields decreased under stressful conditions, with the effect on $\varphi_{\text {Eo }}$ being larger than that on $\varphi_{\text {Po }}$ and that on $\varphi_{\text {Ro }}$ was still larger, showing the efficiencies of the intermediate energy transduction. The performance index $\left(\mathrm{PI}_{\text {total }}\right)$ is mainly a stress indicator and is the most sensitive parameter for the JIP-test, which includes partial 'potentials' for energy conservation (Kalaji et al. 2016, Kalaji et al. 2018a). Note that a negative value for $\mathrm{PI}_{\text {total }}$ indicates 'loss' and a positive value indicates 'gain' for energy conservation (Yusuf et al. 2010). We observed that the $\mathrm{PI}_{\text {total }}$ of LI-treated and LT-treated plants exhibited the increase showing 'gain' after recovery process, while the smaller increase (not significant) was observed after LL-treatment showing plants subjected to LL stress had a poor ability for energy conservation.

Plants, subjected to different environmental stresses, are continuously producing $\mathrm{ROS}$ such as $\mathrm{H}_{2} \mathrm{O}_{2}$ (Cao et al. 2019). Generally, these ROS are unstable and highly reactive molecules, presenting a challenge to plant organs. If left uncontrolled, ROS can cause oxidative damage by causing disruption of membrane lipids, denaturation of proteins or disruption of DNA chain reactions, ultimately leading to cell death (Pintó-Marijuan and Munné-Bosch 2014). In present study, the ROS burst severely damaged the cell membrane integrity according to respective MDA values under adverse stresses (Fig. 5). However, plants have developed ROS-scavenging enzymes, such as POD, CAT, and SOD, that reduce ROS to maintain an adequate reduction/oxidation (redox) balance (Xu et al. 2019). In our experiments, all treatments increased the activity of the above enzymes (Fig. 4), indicating that the strawberry seedlings started their self-protection mechanisms, which enabled them to adapt to the external environment and reconstruct the balance between ROS production and scavenging by regulating the activity of ROS-scavenging enzymes (Das and Roychoudhury 2014, Mittler 2017). After $15 \mathrm{~d}$ of recovery, the activity of POD, CAT, and 
SOD returned to the control level under LI stress, but not under LT and LL stresses, which indicated that LL and LT stresses broke the balance of the production and scavenging of ROS, and this break was irreversible.

\section{References}

Aebi H.: Catalase in vitro. - Method. Enzymol. 105: 121-126, 1984.

Allen D.J., Ort D.R.: Impacts of chilling temperatures on photosynthesis in warm-climate plants. - Trends Plant Sci. 6: 36-42, 2001

Ansari W.A., Atri N., Singh B. et al.: Morpho-physiological and biochemical responses of muskmelon genotypes to different degree of water deficit. - Photosynthetica 56: 1019-1030, 2018.

Baker N.R.: Chlorophyll fluorescence: a probe of photosynthesis in vivo. - Annu. Rev. Plant Biol. 59: 89-113, 2008.

Cao L., Jin X., Zhang Y.: Melatonin confers drought stress tolerance in soybean (Glycine $\max$ L.) by modulating photosynthesis, osmolytes, and reactive oxygen metabolism. Photosynthetica 57: 812-819, 2019.

Coleman W.K., Greyson R.I.: The growth and development of the leaf in tomato (Lycopersicon esculentum). I. The plastochron index, a suitable basis for description. - Can. J. Bot. 54: 24212428, 1976.

Das K., Roychoudhury A.: Reactive oxygen species (ROS) and response of antioxidants as ROS-scavengers during environmental stress in plants. - Front. Env. Sci. 2: 53, 2014.

Dhindsa R.S., Plumb-Dhindsa P., Thorpe T.A.: Leaf senescence: correlated with increased levels of membrane permeability and lipid peroxidation, and decreased levels of superoxide dismutase and catalase. - J. Exp. Bot. 32: 93-101, 1981.

Farquhar G.D., Sharkey T.D.: Stomatal conductance and photosynthesis. - Ann. Rev. Plant Physio. 33: 317-345, 1982.

Gerganova M., Popova A.V., Stanoeva D. et al.: Tomato plants acclimate better to elevated temperature and high light than to treatment with each factor separately. - Plant Physiol. Bioch. 104: 234-241, 2016.

Gill S.S., Tuteja N.: Reactive oxygen species and antioxidant machinery in abiotic stress tolerance in crop plants. - Plant Physiol. Bioch. 48: 909-930, 2010.

Guidi L., Calatayud A.: Non-invasive tools to estimate stressinduced changes in photosynthetic performance in plants inhabiting Mediterranean areas. - Environ. Exp. Bot. 103: 42-52, 2014.

Hodges D.M., DeLong J.M., Forney C.F., Prange R.K.: Improving the thiobarbituric acid-reactive-substances assay for estimating lipid peroxidation in plant tissues containing anthocyanin and other interfering compounds. - Planta 207: 604-611, 1999.

Jurczyk B., Grzesiak M., Pociecha E. et al.: Diverse stomatal behaviors mediating photosynthetic acclimation to low temperatures in Hordeum vulgare. - Front. Plant Sci. 9: 1963, 2019.

Kadir S., Sidhu G., Al-Khatib K.: Strawberry (Fragaria $\times$ ananassa Duch.) growth and productivity as affected by temperature. - HortScience 41: 1423-1430, 2006.

Kalaji H.M., Bąba W., Gediga K. et al.: Chlorophyll fluorescence as a tool for nutrient status identification in rapeseed plants. Photosynth. Res. 136: 329-343, 2018 b.

Kalaji H.M., Jajoo A., Oukarroum A. et al.: Chlorophyll a fluorescence as a tool to monitor physiological status of plants under abiotic stress conditions. - Acta Physiol. Plant. 38: 102, 2016.
Kalaji H.M., Rastogi A., Živčák M. et al.: Prompt chlorophyll fluorescence as a tool for crop phenotyping: An example of barley landraces exposed to various abiotic stress factors. Photosynthetica 56: 953-961, 2018a.

Kwak S.S., Kim S.K., Lee M.S. et al.: Acidic peroxidases from suspension-cultures of sweet potato. - Phytochemistry 39: 981-984, 1995.

Li H., Li T., Gordon R.J. et al.: Strawberry plant fruiting efficiency and its correlation with solar irradiance, temperature and reflectance water index variation. - Environ. Exp. Bot. 68: 165-174, 2010.

Li X.G., Meng Q.W., Jiang G.Q., Zou Q.: The susceptibility of cucumber and sweet pepper to chilling under low irradiance is related to energy dissipation and water-water cycle. Photosynthetica 41: 259-265, 2003.

Liu Y., Xu Q., Li W. et al.: Long-term high light stress induces leaf senescence in wheat (Triticum aestivum L.). - Photosynthetica 57: 830-840, 2019.

Lu T., Meng Z., Zhang G. et al.: Sub-high temperature and high light intensity induced irreversible inhibition on photosynthesis system of tomato plant (Solanum lycopersicum L.). - Front. Plant Sci. 8: 365, 2017.

Lu T., Yu H., Li Q. et al.: Improving plant growth and alleviating photosynthetic inhibition and oxidative stress from low-light stress with exogenous GR24 in tomato (Solanum lycopersicum L.) seedlings. - Front. Plant Sci. 10: 490, 2019.

Maxwell K., Johnson G.N.: Chlorophyll fluorescence a practical guide. - J. Exp. Bot. 51: 659-668, 2000.

Mittler R.: ROS are good. - Trends Plant Sci. 22: 11-19, 2017.

Munné-Bosch S., Pintó-Marijuan M.. Free Radicals, Oxidative Stress and Antioxidants. - In: Thomas B., Murray B.G., Murphy D.J. (ed.): Encyclopedia of Applied Plant Sciences. Pp. 16-19. Academic Press, Amsterdam 2016.

Netto A.T., Campostrini E., de Oliveira J.G., Bressan-Smith R.E.: Photosynthetic pigments, nitrogen, chlorophyll a fluorescence and SPAD-502 readings in coffee leaves. - Sci. Hortic.-Amsterdam 104: 199-209, 2005.

Pintó-Marijuan M., Munné-Bosch S.: Photo-oxidative stress markers as a measure of abiotic stress-induced leaf senescence: advantages and limitations. - J. Exp. Bot. 65: 3845$3857,2014$.

Shu S., Tang Y., Yuan Y. et al.: The role of 24-epibrassinolide in the regulation of photosynthetic characteristics and nitrogen metabolism of tomato seedlings under a combined low temperature and weak light stress. - Plant Physiol. Bioch. 107: 344-353, 2016.

Singh S., Singh P.: Effect of temperature and light on the growth of algae species: A review. - Renew. Sust. Energ. Rev. 50: 431-444, 2015a.

Singh S.P., Singh P.: Effect of temperature and light on the growth of algae species: A review. - Renew. Sust. Energ. Rev. 50: 431-444, 2015b.

Suzuki N., Koussevitzky S., Mittler R., Miller G.: ROS and redox signalling in the response of plants to abiotic stress. Plant Cell Environ. 35: 259-270, 2012.

Tsikas D.: Assessment of lipid peroxidation by measuring malondialdehyde (MDA) and relatives in biological samples: Analytical and biological challenges. - Anal. Biochem. 524: 13-30, 2017.

Xu C., Yang Z., Wang M. et al.: Effects of low temperature on photosynthesis and antioxidant enzyme activities of Panax notoginseng during seeding stage. - Int. J. Agric. Biol. 21: 1279-1286, 2019

Xu P.L., Guo Y.K., Bai J.G. et al.: Effects of long-term chilling on ultrastructure and antioxidant activity in leaves of two cucumber cultivars under low light. - Physiol. Plantarum 132: 
467-478, 2010

Yamamoto Y., Kai S., Ohnishi A. et al.: Quality control of PSII: behavior of PSII in the highly crowded grana thylakoids under excessive light. - Plant Cell Physiol. 55: 1206-1215, 2014.

Yang Z.Q., Yuan C.H., Han W. et al.: Effects of low irradiation on photosynthesis and antioxidant enzyme activities in cucumber during ripening stage. - Photosynthetica 54: 251-258, 2016.

Yusuf M.A., Kumar D., Rajwanshi R. et al:: Overexpression of $\gamma$-tocopherol methyl transferase gene in transgenic Brassica juncea plants alleviates abiotic stress: Physiological and chlorophyll a fluorescence measurements. - BBABioenergetics 1797: 1428-1438, 2010.

Zhang Y.T., Wang G.X., Dong J. et al.: Recent state in strawberry production and research in China. - ISHS Acta Hortic. (VI International Strawberry Symposium) 842: 627-630, 2009.

(C) The authors. This is an open access article distributed under the terms of the Creative Commons BY-NC-ND Licence. 